\title{
A Study to Assess the Awareness of Justice, Equality and Equity -Amongst Homeopathic Practitioners in Practice
}

\author{
Premalata Rotti ${ }^{1}$, Kiran Patil ${ }^{2}$, Girish Moogi ${ }^{3}$, Rinku Porwal $^{4}$ \\ ${ }^{1}$ Assistant Professor, Department Repertory \\ ${ }^{2}$ Professor, Department Organon of Medicine \\ ${ }^{3}$ Principal, Department Materia Medica \\ ${ }^{4}$ Assistant Professor, Department Forensic Medicine \\ A.M. Shaikh Homoeopathic College, Belagavi, Karnataka. \\ Corresponding Author: Premalata Rotti \\ E-mail: drpremlatarotti@yahoo.in
}

\begin{abstract}
Background: Homoeopathy, a holistic science deals with mental, emotional and physical symptoms of the patient during treatment. It demands intricate consultation with broad questions to elicit subjective symptoms and life experiences, enabling an understanding of the patient and connecting the psychological and physiological symptoms. This study aims to gain an in - depth understanding and perception about awareness, justice, equality; and equity amongst Homoeopathic practitioners while treating individual patients according to the set principles and give a fair, justified and equal opportunity to every individual who seeks help from homoeopathy. Methodology: A cross sectional observational survey study was conducted amongst homoeopathic practitioners, teaching faculty and post graduate students of homoeopathic medical colleges of Belagavi for a period of 2 months. Data were collected using Self constructed questionnaire with Closed-end questions, validated by face validity and pilot study. The data was analyzed with item response theory and the results statistically procured with SPSS V.19 software, were interpreted for conclusion.

Result: 165 participants (of 200 questionnaires distributed) responded on awareness of justice, equality and equity amongst homoeopathic practitioners of which, $56.84 \%$ were aware, $29.15 \%$ were unaware and $14 \%$ were doubtful.

Conclusion: This survey encapsulates that $57 \%$ of homoeopathic practitioners were aware about justice equality and equity in practice. Of which- Justice - aware (56.6\%), Unaware (37.87\%), and doubtful (5.45\%), Equality- aware (49\%), Unaware (44.53\%), and doubtful (6.36\%) and Equityaware $(88.48 \%)$, Unaware (4.23\%), and doubtful (7.27\%).
\end{abstract}

Keywords: Justice, equality, equity, homoeopathy.

\section{INTRODUCTION}

Homoeopathy, a holistic science deals with mental, emotional and physical symptoms of the patient during treatment. It demands intricate consultation with broad questions to elicit subjective symptoms and life experiences, enabling an understanding of the patient and connecting the psychological and physiological symptoms. This study aims to gain an in-depth understanding and 
perception about awareness, justice, equality; and equity amongst Homoeopathic practitioners while treating individual patients according to the set principles and give a fair, justified and equal opportunity to every individual who seeks help from homoeopathy.

\section{Technical meaning of the commonly used terms in ethics}

Equity: understand and give people what they need to enjoy full, healthy lives

Equality: in contrast, aims to ensure that everyone gets the same things in order to enjoy full, healthy lives [1].

Justice: fairness, righteousness. Justice is the morally fair and right state of everything [2].

Justice was about rightness (or "straightness"). To do justly was simply to act in conformity with an enlightened sense of moral righteousness [3].

According to World Health Organization [WHO], Homoeopathy is fastest growing \& 2nd most widely used system in the world [4]. More than $70 \%$ of population believed that Homoeopathy is better than other systems, reason for that being no side effects, low cost of treatment, easy to take medicines which corresponds with the study of Singh and others [5].

According to the Government of India report, around 10\% of India's population depends solely on Homoeopathy for their healthcare [6]. Homeopathy is a gentle, complete system of natural medicine. Patients are treated as a whole - physically, mentally and emotionally - not just for the medical complaint they present with. Homeopaths observe that homeopathic medicine appears to stimulate the individual's natural ability to self-heal and reduce the intensity of their symptoms [7]. It is a low-cost, nontoxic system of medicine used by hundreds of millions of people worldwide [8]. In India, where homoeopathy is a national medical system.

India is arguably unique in the extent to which it has recognized homoeopathy as a legitimate system of medicine. Despite originating in Germany, the Indian government has bestowed it with the status of a national medical system [9]. Homoeopathy, if practiced properly, is cheaper, safer and effective for many ailments [10].

\section{Objective}

To explore an in-depth understanding and perception about awareness of justice, equality; and equity amongst Homoeopathic practitioners while treating individual patients.

\section{METHODOLOGY}

Type of research: A cross-sectional, observational survey on awareness about justice, equality and equity amongst homoeopathic practitioners in practice was conducted.

Duration of study: 2 months (June and August 2019.)

Tools used: Our study began with item response theory based on which a self-constructed questionnaire was developed by us and self-administered, which was filled by participants. The questionnaire was validated by face validity and pilot study. The questionnaire was in English. And was short and simple having ten closed end questions with appropriate options which took 10-15 min to complete. It included two sections;

- The first section consisted of individual's personal/social information (The personal/social information included name, age, gender, qualification, designation, department (for academicians) and institution details.)

- The second section contained ten questions regarding individuals' awareness, practice, justice, equality and equity related questions.

Inclusion criteria: For our survey included all academicians from different homoeopathic medical colleges, practitioners and post graduate students in Belagavi district and participants of either sex included.

Statistical tool: Excel Spreadsheet. SPSS version V.19 was used for statistical analysis of the data. 


\section{RESULTS}

A total of 200 questionnaires were distributed, and 165 were filled and returned

- Participation rate $82.5 \%$

Table 1 - Awareness of justice, equality and equity amongst homoeopathic practitioners

\begin{tabular}{|l|l|l|l|}
\hline & Justice & Equality & Equity \\
\hline Yes & $56.6 \%$ & $49 \%$ & $88.48 \%$ \\
\hline No & $37.87 \%$ & $44.53 \%$ & $4.23 \%$ \\
\hline
\end{tabular}

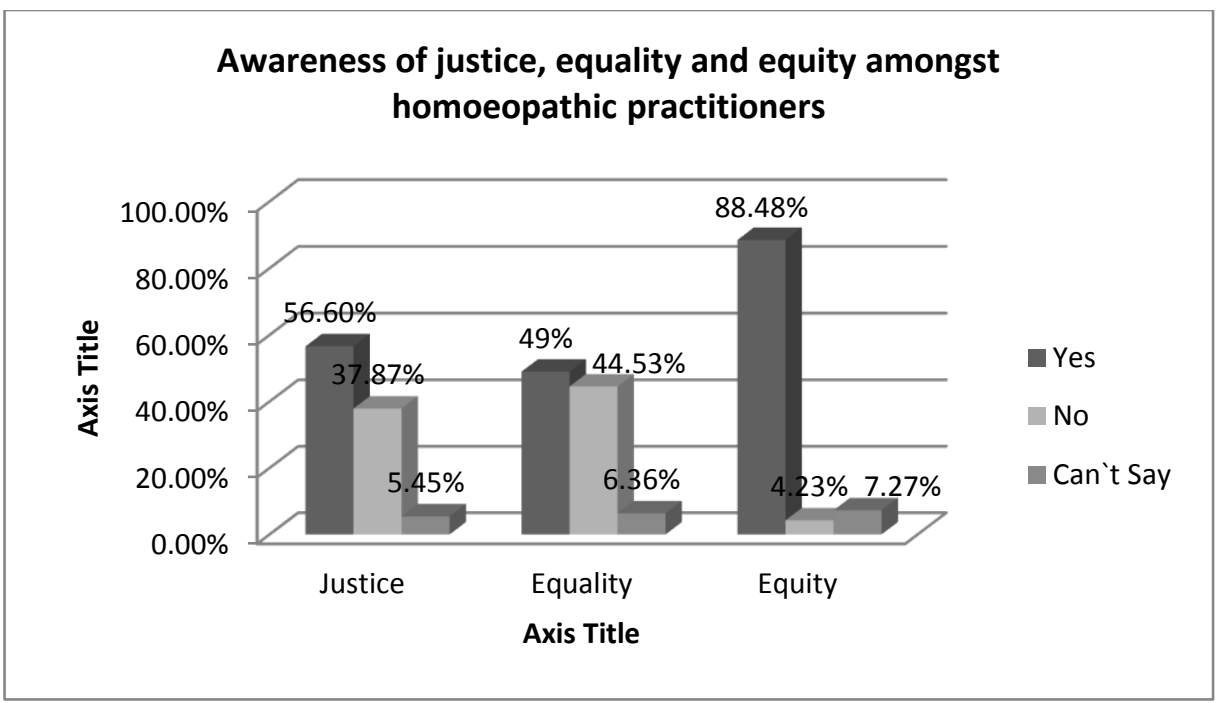

\section{GENDER}

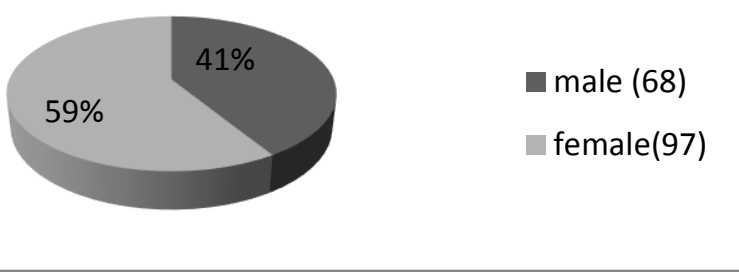

\section{OCCUPATION}

- ACDEMICIANS(80) PRACTICE(22) - PG(63)

$38 \%$

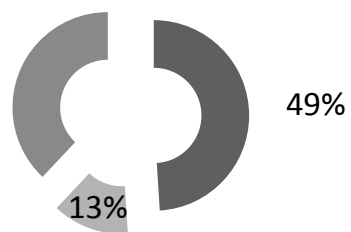


Table 2 - Responses of the participants

\begin{tabular}{|c|c|c|c|}
\hline Topic & Yes & No & Can't say \\
\hline \multirow{3}{*}{ Awareness } & 58 & 58 & 49 \\
\cline { 2 - 4 } & 68 & 53 & 44 \\
\hline \multirow{3}{*}{ Principles } & 26 & 74 & 65 \\
\cline { 2 - 4 } & 145 & 10 & 10 \\
\hline \multirow{3}{*}{ Justice } & 25 & 124 & 16 \\
\cline { 2 - 4 } & 162 & 1 & 2 \\
\hline \multirow{3}{*}{ Equality } & 150 & 2 & 13 \\
\hline \multirow{3}{*}{ Equity } & 12 & 145 & 8 \\
\cline { 2 - 4 } & 145 & 8 & 12 \\
\hline
\end{tabular}

The results were analysed using regression and correlated to awareness (independent variable) with-principles, justice, equality and equity (dependent variables). The observations were -

- Awareness has a correlation with principles ( $p$ value $-0.000549<0.05$ ), the interpretation can be that being aware about homoeopathy can affect using principles in practice.

- Awareness has correlation with justice ( $p$ value $-0.0016<0.05$ ), hence we observe that awareness about homoeopathy helps practitioners to treat patients judiciously.

- Awareness has no correlation with equality ( $p$ value $-0.254>0.05$ ), being aware in no way helps a practitioner to treat every patient equally.

- Awareness has no correlation with equity ( $p$ value $-0.23>0.05$ ), statistically we cannot correlate awareness about homoeopathy and equity during practice, on the contrary this study shows that $88.5 \%$ participants think that practitioners are treating every patient equitably.

\section{DISCUSSION}

Homeopathy seems well suited for use in rural areas where the Infrastructure, Equipment, and Drugs needed for Conventional Medicine cannot be provided [4].

In our study $56.6 \%$ (justice) of participants think the same. When we explored about equality in terms of treatment being economical for patients our study shows that $90 \%$ agree with this which is also corresponds with previous studies. Homoeopathic consultation happens as per law of individualization. Hahnemann in $6^{\text {th }}$ edition of organon quotes - This individualizing examination of a case of disease, for which I shall only give in this place general directions, of which the practitioner will bear in mind only what is applicable for each individual case [11] (equity).

In our study questions about equity proves it where $88 \%$ participants agree with it.

\section{Limitation of Study}

The study was restricted to only 1 district.

\section{CONCLUSION}

This study is one of its unique kind where no such studies in the field of medical sciences, in particular homoeopathy were carried out in the past. The study revealed a valid data about the awareness about ethical practices amongst the homoeopathic practitioners. 


\section{Recommendation}

An extensive study is required not only in Belagavi district but other parts too, to have a wider perspective. This study may be further explored to wider areas across state wise and nationwide to assess the ethical awareness amongst the medical practitioners of various streams.

\section{REFERENCES}

1. Folger R. Rethinking equity theory. InJustice in social relations (pp. 145-162). Springer, Boston, MA; 1986.

2. Deutsch M. Equity, equality, and need: What determines which value will be used as the basis of distributive justice?. J Soc Issues 1975;31(3):137-49.

3. Kolm SC. Justice and equity. MIT Press; 2002.

4. Pandey MM, Rastogi S, Rawat AK. Indian traditional ayurvedic system of medicine and nutritional supplementation. Evidence Based Complementary and Alternative Medicine 2013;2013.

5. Sarangi MR, Pramanik A, Gupta J, Prasad R, Singh P, Shah M, Upadhyay AK, Jain S, Pandey A, Kumar A, Khurana A. A survey regarding awareness and beliefs about Homoeopathy among general population during Magh Mela at Allahabad, Uttar Pradesh, India. Indian J Res Homoeopathy 2019;13:12-21.

6. Prasad R. Homoeopathy booming in India. Lancet 2007;370(9600):1679-80.

7. Jonas WB, Kaptchuk TJ, Linde K. A critical overview of homeopathy. Ann Intern Med 2003;138(5):393-9.

8. Bornhöft $G$, Wolf $U$, von Ammon K, Righetti M, Maxion-Bergemann S, Baumgartner S, Thurneysen A, Matthiessen PF. Effectiveness, safety and cost-effectiveness of homeopathy in general practice-summarized health technology assessment. Complement Med Res 2006;13(2):1929.

9. Singh B, Kumar M, Singh A. Evaluation of implementation status of national policy on Indian systems of medicine and homeopathy 2002: Stakeholders' perspective. Ancient Science of Life 2013;33(2):103.

10. Pustiglione M, Goldenstein E, Checinski YM. Homeopathy: a brief description of this medical specialty. Rev de Homeo 2017;80(3/4):1-5.

11. Hahnemann S. Organon of medicine. B. Jain Publishers; 2002.

Acknowledgements: Nil

Funding: Nil

Conflict of interest: None 